tan graves caracteres el divorcio con la realidad humana. El escepticismo, la persecución del goce sin freno, los esfuerzos por alcanzar originalidad a cualquier precio, son las características generales que nos hacen encontrar en la inquietud de 1930 al subjetivismo romántico.

La tradición de la realidad humana y social se ha mantenido, indudablemente, a través del período d'après-guerre. No aparece una literatura proletaria; la voz universal de Romain Rolland encuentra escaso eco; pero hay una literatura nacional que continúa la corriente de la vida: André Chamsom, Henry Pourrat, Lucien Gachon, Jean Giono. Una reacción se manifiesta con Marcel Arland (Premio Goncourt 1929), Marcel Aymé, Georges David, Eduardo Peisson, todos jóvenes escritores de porvenir, que no se contentan con el refinamiento de la psicología individual o el juego del estetismo. $\mathrm{Y}$ esta reacción es hoy innegable y tan profunda que su existencia ha sido sancionada por la moda, creando la escuela del populismo.

Pero el neo-romanticismo no ha muerto, porque una nueva orientación literaria no alcanza a ahogar una corriente espiritual de tan profundas causas. Para nosotros, el drama que durante cien años ha creado el poeta, desde el dandismo hasta lo sub-consciente, es, ante todo, un drama social. Encontrará desenlace sólo en el retorno a un régimen que permita la realización de un esfuerzo colectivo, dentro de una concepción universalista del mundo. Sólo un régimen de esa naturaleza permitirá al individualismo restablecer la armonía entre la vida interior del hombre y las aspiraciones de una comunidad espiritual.-A. H A B A R U.

Exclusivo para Atenea en Chile.

\title{
Louis Brauquier, el poeta de los puertos
}

โ(D) RAUQUIER es poco conocido en Francia y totalmente ignorado en América. Su poesía ruda, libre y, para algunos, algo romántica, no cuadra con las tendencias a la moda. Según mi modesta opinión, Brauquier es ante todo el marino, el hombre vivido que ama su oficio sobre todas las cosas, no por una comprensión espontánea del presente, sino por ser ese oficio el producto de un ten pe- 
ramento, de una estructura sentimental que lo llevó a la vida del mar. Brauquier es el marino en sí, y diría más, es la personificación de todos aquellos poetas mudos, ignorados, que él llamó tan gráficamente

Les grands marins, blancs de rève Dérivant sur la ville nue.

Es el poeta mudo que «supo» expresarse y ser admirable con solo enumerar la realidad. Hubiera parecido lógico llamar a Brauquier el poeta del mar y no de los puertos, pero yo no creo en la poesía de alta mar, a menos que nos refiramos a la poesía del barco mismo....

La Poesía, lo Bello (con mayúscula, señor Latcham....) es esencialmente humano. Inutil me parece todo esfuerzo por tratar de evidenciarla en lo abstracto, en lo divino, en lo estático. Poesía es vida, es paisaje sincronizado con el alma, es pasión, es calor de las criaturas, no sutileza, innensidad, psyché.

El mar es una gran abstracción, donde los hombres sueñan que partieron y sueñan que volverán. En él no hay poesía, como no la hay en el dormir ni la hay en la muerte. La poesía está en la nostalgia del puerto dejado y en el deseo de volver a él. En el mar sólo está el prestigio: aureola triste de los que parten, virginidad viril de los que vuelven y para ambos el triunfo sobre el obstáculo líquido, sobre la ausencia sin amor, sobre la indiferencia de los hombres desconocidos con que el azar forma las tripulaciones.

Todo esto ¡cómo lo ha sentido Brauquier y con qué amor escribe en uno de sus poemas!:

\section{...je voudrais}

Lorsque mon corps séra mélangé à la terre,

Que vous mettiez mon nom en poupe d'un voilier.

Todas las etapas y las contingencias de la vida marina se dejan ver a través de sus poemas.

Se adivina primero al grumete, ese personaje que no corresponde a nuestros niños, ya que éstos son la imagen del marino adulto: l'enfant de la mer. El grumete es menos aún, algo así como el perrito juguetón, ajeno a toda idea sensual y moral. Es el enamorado del mundo exterior, del bronce que brilla, de la cubierta blanca de frote, de la vela henchida y crepitante. Para él la hembra es una "mise en scéne»; el compañero, un espejo en que descubre chistosamente su propio ser. Otro 
"yo» con quien responde al sinnúmero de llamados gozosos del mundo exterior.

Un bon rire d'intimité

Remontait de ce sauvetage

Nous retrouvions sur nos visages

Chaque morsure de l'été.

Aucune tendresse nocturne

N'attendait notre solitude;

Notre vie avait ce gout rude

Des maisons neuves, blanches, vides.

Et $\mathrm{la}$ mer nous ayant repris,

Le trois mâts "Orlando?, de Gênes,

Qui appareillait dans le port

Fût un instant tout notre amour.

Más adelante encontramos entre sus versos al adolescente apasionado que observa con curiosidad todo ese exterior del amor, tan conocido ya en su infancia pero visto entonces con otros ojos, burlescamente, como una fantasía de los "grandes». Los niños acomodados son inocentes por ignorancia. La inocencia de los rapazuelos es diversa. Ellos lo saben todo porque han nacido en la promiscuidad, pero se abstienen con la inocencia de los retoños que aguardan su primavera.

Regarde, le matin a repeint les tartanes;

Une femme à grande eau, lave sur le trottoir

Les ordures et le sang de la nuit courtisane.

Nos corps sont innocents. Nous tenons tout l'espoir.

Por fin el marino ya hombre, en vísperas de volver al mar:

Une tendresse marine

Aiguisait plus d'un amour,

Et poussait à la souffrance

Le goat des derniers baisers.

Ultimos momentos antes de la partida, robados al sueño después del cuarto de guardia:

Nous arrachions au sommeil

Déja plein du lendemain

Des morceaux de ce bonheur

Qu'on doit consommer sur place.

Des vermouths italiens

Saignaient sur le blanc des tables 
Tout secoué d'amitié,

Le bar oscillait comme en mer.

¿Quién podrá negarse a sentir el puerto en estos dos versos simples como el alma marina?:

La tendresse des Ports est noyé d'amertume;

Des lumières dans l'eau et dans l'aii bleu et noir.

Y qué cuadro ultra-moderno en estas pinceladas atrevidas como las de un boceto de Picasso:

Tombait aussi un souvenir de femme

De la poche droite du révolver,

Et les trousseaux d'acier des clés infames,

Dévérrouillant dans des hotels pas chers

Les attendries portes de la jeunesse.

Tandis qu'un grand soleil adolescent

Devorait dans la rue des places au vin blanc

Et des salades vertes de platanes.

En mis largas correrías marinas he podido evidenciar dos sentimientos que caracterizan al hombre de mar: el amor a su barco y una tierna solicitud por la juventud ingenua de las tripulaciones. Hay quienes pretenden torcer el verdadero significado de este platonismo... Han caído en un error por exceso de malicia: la pureza que el mar comunica a esos hombres rudos es tan grande como la sed de amor que en ellos despierta. El pretexto del aislamiento sexual no pasa de ser un pretexto. El verdadero mal no está en el mar sino en tierra y se traduce las más de las veces por el consejo que sería casi maternal si el tono rudo y displicente no encerrara un rubor celoso. del!:

iCon qué frases implora Brauquier a las mujeres del bur-

Soyez bonnes ce soir aux hommes d'équipage

Qui descendent vers vous dans l'ombre de l'escale,

Avec des coeurs si lourds et de si doux langages

Etrangers, mots chantés dans les mâts de l'espace.

Qué bien conoce a esos compañeros de las largas veladas de invierno, en el castillo de proa, bajo la lámpara-cardán. Cómo teme a esas ruidosas rameras del puerto, capaces de trizar con una carcajada el delicado cristal de sus sueños adolescentes. 
Soyez simples pour ceux que cette mer vous donne Et que leur solitude épouse votre mal, Pour les hommes du Pont, pour ceux de la Machine, Pour le novice ému du Port méridional.

Se los imagina inquietos, vacilantes, entre las callejuelas vecinas a los muelles, sintiendo aún bajo sus pies el balanceo de la marejada.

Un désir plus profond que la nuit maritime

Descend de leur échèlle en face des grands docks,

Et les roule, perdus, sur les quais de la ville

Balancée au remous nocturne des vaisseaux.

El ya es un hombre, ya ha pasado por esas noches llenas de esperanzas divinas, a las que siguen esos despertares da hastío, «la bouche séche et la mort dans l'âme». Conoce le tristeza infinita del amor no saciado, de la ternura perdida. Sólo le queda un consuelo: el mar, el purificador supremo, el creador de ideales que tal vez se realicen en lejanos países, más allá del horizonte... .

Puisque tout meurt ici, avant que tout renaisse

Dans le matin, que rien ne fait prévoir encore,

Que les hommes trahis, auprès de leur maitrèsse

Epuisent la torture et l'orgueil d'être forts.

Qu'ils cherchent leur faiblesse à l'âme puérile,

Dans les chambres vaicues par leur pureté,

Qu'ls attendent le jour qui va prendre les lles,

Sur la mer rafraichie et l'horizon lavé.

Nadie mejor que Brauquier ha sabido llevar el lirismo del puerto a una nota emotiva alta a la vez que profunda:

Entends-tu? le Port en tristesse

Fait craquer les barques bleus.

Raide morts, dans leur cales sèches

Des voiliers montent à Dieu.

$Y$ esos atardeceres en los bares escondidos «comme un trou d'ombre qui regarde les mâts», esos abándonos espléndidos a la caída de la tarde:

Fume ta pipe, vois le soir vient te prendre

La main d'un geste doux,

Comme un consommateur moins discret et plus tendre Qui triche au jeu, avec la nuit sur ces genoux. 
En sus últimos años nos dejó algunas estrofas admirables, nostálgicas y sencillas como toda emoción sincera cantada por el que no pretende ser poeta:

Le regret des jours marins

Nous fait l'âme triste ensemble.

Bastien, parle-moi du temps

Chaleureux, où, vers d'autres lles,

Vous pressentiez à plusieurs milles

L'odeur douce de Ceylan.

Nous sommes toujours des enfants.

Parle, il n'y a rien qui vaille

La souffrance que j'ai là.

Tu racontes sans savoir...

Tu ne penses qu'a toi même,

Indifférence que $\mathrm{j}$ 'aime,

Souvenirs rouges et noirs.

Parle-moi des mers indiennes.

En 1929 estaba yo en Marsella. Había terminado de leer Bar d'escale, y comenzaba L'Au-delà de Suez, su segunda obra, cuando vi en los periódicos la muerte del poeta, allí en Marsella, la ciudad que lo vió nacer, el puerto por excelencia. Brauquier merece figurar al lado de J. Richepin, de Loti, de Farrère, como poeta del mar. Para mí es superior a todos éstos porque amo Marsella....

En Chile comenzamos a darnos cuenta que debemos ocuparnos del mar. Mariano Latorre, Salvador Reyes, Echeverría Larrazábal, son los mejores exponentes de nuestras letras marinas. A ellos van dirigidas principalmente estas citas del poeta de los puertos. Brauquier puede ser una fuente de inspiración viril y sincera. En todo caso es un amigo que nos convida a su festín.

Mangez ces fruits amers dont la pulpe est saignante Et buvez du vin blanc.

Que je sois près de vous dans vos soirées brulantes, Sur le Port innocent. 